\title{
ROLE OF FLY ASH ON STRENGTH PROPERTIES OF REJUVENATED SOIL CEMENT FOR PAVEMENT MATERIALS
}

\author{
Prinya CHINDAPRASIRT ${ }^{1}$, Apichit KAMPALA ${ }^{2,{ }^{*}}$, Pattawitchaya DAPROM $^{3}$, \\ Peerapong JITSANGIAM ${ }^{4}$, Suksun HORPIBULSUK ${ }^{5}$
}

${ }^{1}$ Sustainable Infrastructure Research and Development Center, Department of Civil Engineering, Faculty of Engineering, Khon Kaen University, Thailand; and Academy of Science, The Royal Society of Thailand, Dusit, Bangkok, 10300, Thailand.

2 Department of Civil Engineering, Faculty of Engineering, Rajamangala University of Technology Isan, Khon Kaen Campus, Srichan Rd., Muang District, Khon Kaen, 40000, Thailand.

${ }^{3}$ Department of Civil Engineering, Rajamangala University of Technology Isan, Sakon Nakhon Campus, Sakon Nakhon, 47160, Thailand.

${ }_{5}^{4}$ Department of Civil Engineering, Chiang Mai University, Chiang Mai, 50000, Thailand.

${ }^{5}$ Center of Excellence in Innovation for Sustainable Infrastructure Development, Suranaree University of Technology, Nakhon Ratchasima, 30000, Thailand.

corresponding author: apichit.ku@rmuti.ac.th

\section{Abstract}

Stabilization with cement is the most commonly used technique for the improvement of soil physical, mechanical, and engineering properties. This research reported on the properties of the rejuvenation for recycled soil cement with incorporation of fly ash (FA). The study showed that the specific gravity of Rejuvenated Soil Cement (RSC) decreased with increasing FA. The free swell ratio and linear shrinkage of RSC were significantly decreased with the increase in FA. The maximum dry unit weight of RSC increased with increasing FA up to the optimum FA content of $20-25 \%$. The optimum water content in compaction was relatively constant with the increase in FA. Particularly, the strength improvement in active zone of FA-RSC was influenced by several factors viz., compaction, packing, rehydration, and pozzolanic reaction. As a result, the unconfined compressive strength (UCS) of RSC increased with increase in FA and curing time. This research clearly showed that the rejuvenation of soil-cement with $F A$ as additive was successful. It was also shown that the normalized UCSs of RSC at various curing times could be used to predict the UCSs at 7 and 28 days.
\end{abstract}

\section{Keywords:}

Rejuvenated soil cement; Pozzolanic reaction; Rehydration effect; Unconfined compressive strength; Secant modulus of elasticity.

\section{Introduction}

Soil stabilized by cement known as "soil-cement" is the most widely used technique for soil improvement to increase the strength. Portland cement, lime mixed with fly ash (FA), and other pozzolanic materials are the commonly used ones. The techniques for soil cement stabilization are classified into two types viz., deep mixing, and shallow mixing [1]. The deep mixing improvement is done by using a blade or pressure and thus suitable for soft clay. The moisture content of soil is normally equal to or higher than the moisture of its liquid limit state. Whilst the shallow mixing is applicable for road works at shallow depth. The method of mixing is done with low moisture and the resulting soil mass typically contains air cavities. The shallow mixing of cement and soil generates the soil cement granules. The compaction moisture content is usually equal to or at 1.10 times of the optimum water content (OWC) [2].

The soil cement (SC) strength is improved by the hydration reaction. When water comes into contacted with cement; the cement mixture starts to hydrate and form several hydration products 
including C-A-H (Calcium Aluminate Hydrate), C-S-H (Calcium Silicate Hydrate), and $\mathrm{Ca}(\mathrm{OH})_{2}$ (Calcium Hydroxide) embedded in the soil matrix [3]. In this regard, the cement particle hydrates and creates the hardening skeleton matrix surrounding the soil particles. The hydration reaction increases the $\mathrm{pH}$ value due to $\mathrm{Ca}(\mathrm{OH})_{2}$ dissolution and this enables the reaction with available $\mathrm{SiO}_{2}$ (Silica) and $\mathrm{Al}_{2} \mathrm{O}_{3}$ (Alumina). In addition, silica and alumina from soil can slowly react with free lime ions and gain strength with curing time. This process is called pozzolanic reaction [4]. For shallow mixing, the compacted soil layer contains low moisture content thus a high amount of un-hydrated cement is left within the soil mass. Besides, the hydration reaction also generates $\mathrm{Ca}(\mathrm{OH})_{2}$ which is also left within the soil mass. The presence of $\mathrm{Ca}(\mathrm{OH})_{2}$ increases the risk of unsoundness, and could lead to excessive expansion and damage to the compacted soil [5].

The damaged soil cement road or pavement could be fixed by using the in-situ rejuvenation. The use of pozzolanic material such as FA in the recycled soil cement with re-compacting is thus a good way for the rejuvenation of soil cement pavement. This process will be called "Rejuvenated Soil Cement (RSC)" thereupon. This process also reduced $\mathrm{Ca}(\mathrm{OH})_{2}$ and thus reduce the damage from the influence of unsoundness. In terms of concrete materials, several studies proposed a guideline to mitigate the $\mathrm{Ca}(\mathrm{OH})_{2}$ problem [6] by mixing $\mathrm{FA}$ with cement. In this regard, $\mathrm{SiO}_{2}$, and $\mathrm{Al}_{2} \mathrm{O}_{3}$ rich in $\mathrm{FA}$ react with $\mathrm{Ca}(\mathrm{OH})_{2}$ and form C-S-H and C-A-H. In addition, the use of FA could reduce the cement content [7-8], and increase the concrete tolerance to prevent the damage from a sulfate-chloride solution. [9-10]. In geotechnical engineering, the benefits of FA were observed in many studies such as to improve the soil property by mixing with lime and Calcium Carbide Residue [2, 5-6, 11-15], to decrease cement, and to increase soil tolerance against sulfate attack and loss of strength by wetting and drying cycles [16-17].

Based on the previous studies, it is evidenced that FA has been used in many applications, but there was no study on the RSC yet. Many studies presented the increase of the soil strength from the pozzolanic reaction, whereas there are also other factors which exert influence on the properties of soil cement with FA. For example, the effect of hydration reaction is also influenced by the particles, total mass, size distribution, and compaction. As a consequence, this study explored the general properties, mechanical properties, and engineering properties of RSC using FA as additive. The tested parameters included specific gravity (Gs), consistency index, linear shrinkage, swelling, compaction, and UCS. The outcome of this study should be useful in understanding the influence of FA on soil behaviors and basic properties that dominate the engineering characteristics, and the strength improvement of RSC. Especially, in country where the cementitious material, such as cement, is limited and necessarily recycled. Furthermore, it can also provide the fundamental knowledge for the extension to other pozzolans for example the use of rice husk ash for pavement improvement.

\section{Materials and methods}

\subsection{Soil}

The soil was a clayey soil from a location in Nakhon Ratchasima province, Thailand. This soil was selected as it was used for fill, subgrade material, and stabilized with cement for subbase materials. It was taken from a depth of 3 meters. The soil contained high silica and alumina contents $61.15 \% \mathrm{SiO}_{2}$ and $18.076 \% \mathrm{Al}_{2} \mathrm{O}_{3}$ as shown in Table 1. The Gs, liquid limit, plastic limit, and grain size distribution of soil were tested in accordance with the ASTM standards as summarized in Table 2. The soil had Gs of 2.74, liquid limit of $55 \%$ and plastic limit of $27 \%$. The grain size of soil is presented in Fig. 1. This soil was a high plasticity clay $(\mathrm{CH})$ as per the unified soil classification system (USCS).

The free swell ratio (FSR) test of soil was done using method adopted by Prakash and Sridharan [18]. The linear shrinkage of soil was tested following ASTM standard, see Table 2. The FSR of 1.76 and linear shrinkage of $12.7 \%$ were obtained from the tests. 
Table 1: Chemical components of soil, cement, rejuvenated soil cement, and FA.

\begin{tabular}{|c|c|c|c|c|}
\hline Chemical composition & Soil [\%] & Cement [\%] & Rejuvenated soil cement [\%] & Fly ash [\%] \\
\hline $\mathrm{SiO}_{2}$ & 61.15 & 20.90 & 50.19 & 45.69 \\
\hline $\mathrm{Al}_{2} \mathrm{O}_{3}$ & 18.07 & 4.76 & 15.80 & 24.59 \\
\hline $\mathrm{Fe}_{2} \mathrm{O}_{3}$ & 6.18 & 3.41 & 7.21 & 11.26 \\
\hline $\mathrm{CaO}$ & 2.55 & 65.41 & 14.18 & 12.15 \\
\hline $\mathrm{MgO}$ & 5.80 & 1.25 & 4.72 & 2.87 \\
\hline $\mathrm{SO}_{3}$ & 0.05 & 2.71 & 0.72 & 1.57 \\
\hline $\mathrm{K}_{2} \mathrm{O}$ & 4.29 & 0.35 & 3.92 & 0.52 \\
\hline $\mathrm{LOI}$ & 3.44 & 0.96 & 2.85 & 1.23 \\
\hline
\end{tabular}

Table 2: Testing methods.

\begin{tabular}{|c|c|}
\hline Soil grain size (sieve analysis) & ASTM D422-63(2007)e2 \\
\hline Soil grain size (hydrometer) & ASTM D422-63(2007)e2 \\
\hline Gs & ASTM D854-14 \\
\hline Liquid limit and plastic limit & ASTM D4318 - 17e1 \\
\hline Free swell ratio & Prakash and Sridharan [36] \\
\hline Linear shrinkage & ASTM D423-66 (1972) \\
\hline Modified proctor compaction & ASTM D1557 - 12e1 \\
\hline Unconfined compressive strength (UCS) & ASTM D1633 - 17 \\
\hline
\end{tabular}

\subsection{Cement and fly ash}

Portland cement Type 1 was used as it was commonly used for the soil stabilization. FA was from Mae Moh Power Plant, Lampang province, Thailand. The grain size distribution is presented in Fig. 1 while the chemical compositions are shown in Table 1. This FA contained $45.69 \% \mathrm{SiO}_{2}$, $24.59 \% \mathrm{Al}_{2} \mathrm{O}_{3}, 11.26 \% \mathrm{Fe}_{2} \mathrm{O}_{3}$, and $12.15 \% \mathrm{CaO}$; thus, the $\mathrm{FA}$ could be classified as class $\mathrm{F}$ as per ASTM C 618. The Gs of cement was 3.14 and that of FA was 2.30.

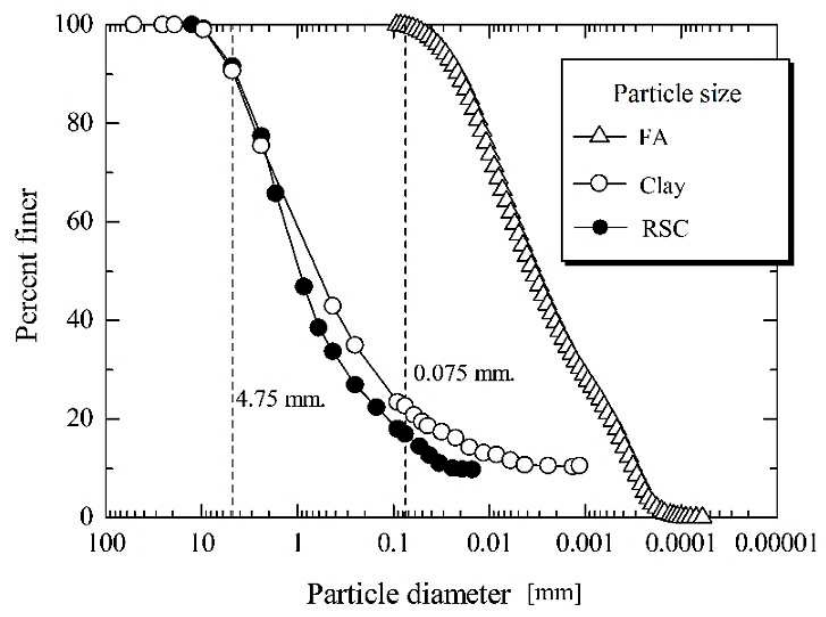

Fig. 1: Grain size distribution of clay, RSC, and FA.

\subsection{Soil cement}

A $4 \times 10 \mathrm{~m}$ soil cement pavement section with $8 \%$ cement content as required for $\mathrm{CH}$ by the standard of ACI 230.1R-90 [19] was prepared. The compaction was done at optimum moisture content of $18 \%$ in 2 layers of $0.1 \mathrm{~m}$ thick using a reversible compactor to obtain a density of at least $95 \%$ of maximum dry unit weight. After compaction, the compacted pavement was covered with a plastic membrane for 28 days and air-cured for 120 days.

Subsequently, the pavement section was broken, and the recycled soil cement sample was obtained. The sample was then crushed and passed through sieve No. 4. The sample before crushing 
and after passing through sieve no. 4 are shown in Fig. 2. The Gs, liquid limit and plastic limit were tested in accordance with ASTM standards. The Gs of 2.74, liquid limit of $50.4 \%$ and plastic limit of $30.4 \%$ were obtained from the tests. Based on the Unified Soil Classification System (USCS), the RSC was classified as high plasticity (MH). The grain size distribution of soil-cement is shown in Fig. 1 and the chemical components of this soil and RSC are shown in Table 1.
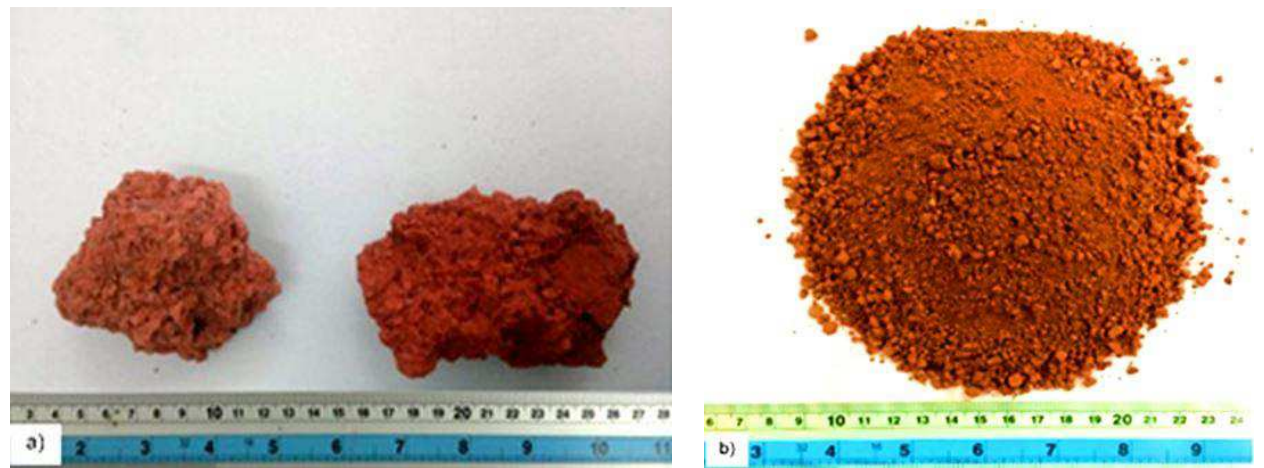

Fig. 2: Recycled soil cement sample: a) before crushing, and b) crushed and passed sieve No. 4.

Fig. 3 presents the XRD patterns of soil and soil cement. The main component of soil was silica $\mathrm{SiO}_{2}$ in a crystal form. After the improvement with $8 \%$ cement, the XRD showed reduced amount of crystal. The important component of cement hydration product, $\mathrm{CSH}$, was found at $28-29 \circ 2$ Theta.

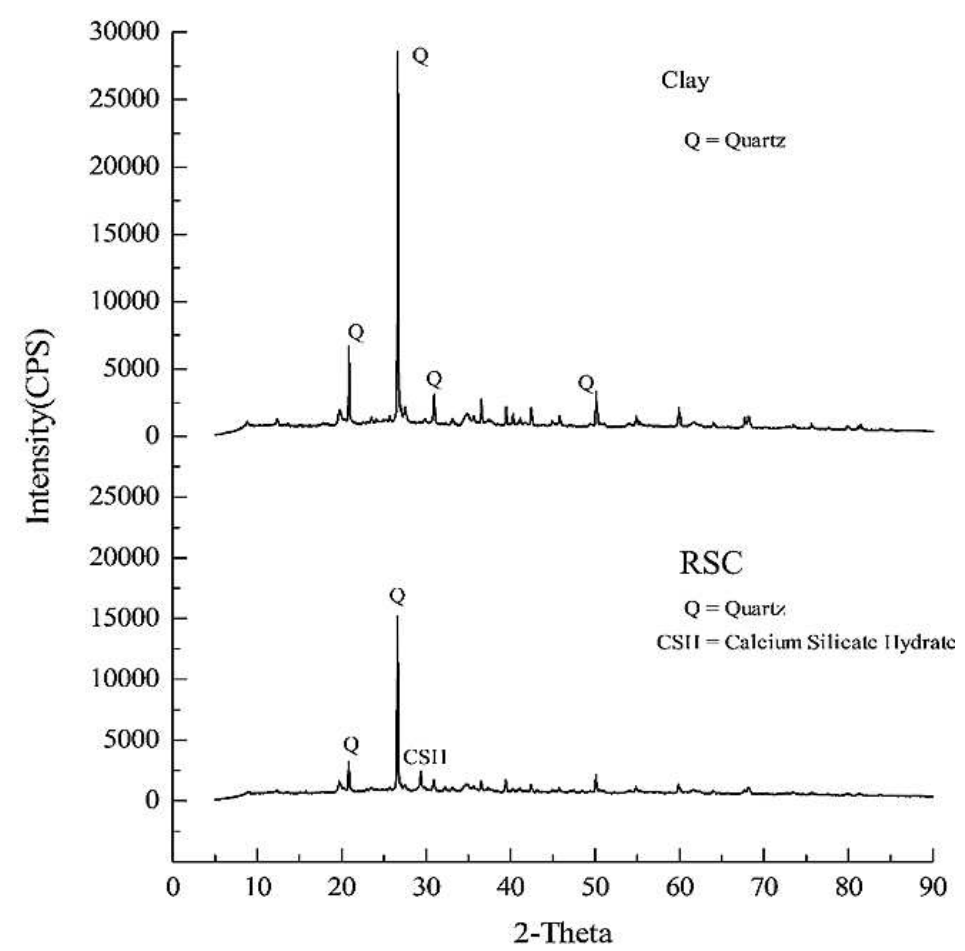

Fig. 3: X-Ray diffraction of soil and RSC.

\subsection{UCS test}

The UCS test was done in accordance with ASTM D1633-17. This test gives a quick result and is timesaving for the compressive strength estimation. The clay and RSC samples mixed with various FA contents cured for 0,7 , and 28 days as shown in Table 3 were tested. The cylindrical sample of 71 $\mathrm{mm}$ in diameter and $142 \mathrm{~mm}$ in height was used. The compaction was done with Modified Proctor compaction as per ASTM D1557 - 12e1 at optimum water content $18 \%$. After the compaction, the sample with mold was wrapped with plastic membrane to prevent loss of moisture. Before testing, the sample was soaked in water for 2 hours so that it was in a saturated state. The displacement rate of $0.16 \mathrm{~mm} /$ minute was used for testing. The secant Young's modulus $E_{50}$ was determined from the UCS test. 
Table 3: Summary of testing programs.

\begin{tabular}{|c|c|c|c|}
\hline Test & Sample & Curing time [days] & FA [\%] \\
\hline \multirow{2}{*}{ Particle size } & Soil & 0 & 0 \\
& Recycled soil cement & 120 & 0 \\
& FA & 0 & 100 \\
\hline \multirow{2}{*}{ Compaction } & Soil & 0 & $0,5,10,15,20,25,30$ \\
& Rejuvenated soil cement & 0 & $0,5,10,15,20,25,30$ \\
\hline \multirow{2}{*}{ Gs } & Soil & 0 & $0,5,7,10,15,20,25,30$ \\
& Rejuvenated soil cement & 28 & $0,5,7,10,15,20,25,30$ \\
\hline \multirow{2}{*}{ Index properties } & Soil & 0 & $0,5,7,10,15,20,25,30$ \\
& Rejuvenated soil cement & 28 & $0,5,7,10,15,20,25,30$ \\
\hline \multirow{2}{*}{ Free swell } & Soil & 0 & $0,5,7,10,15,20,25,30$ \\
& Rejuvenated soil cement & 28 & $0,5,7,10,15,20,25,30$ \\
\hline \multirow{2}{*}{ Linear shrinkage } & Soil & 0 & $0,5,7,10,15,20,25,30$ \\
& Rejuvenated soil cement & 28 & $0,5,7,10,15,20,25,30$ \\
\hline UCS & Rejuvenated soil cement & $0,7,28$ & $0,5,10,15,20,25,30,40,50$ \\
\hline
\end{tabular}

\section{Results}

The results on the change in Gs of soil and RSC with FA after 28 days curing are shown in Fig. 4. The Gs of clay mixed with FA decreased slightly with increasing FA content while the Gs of RSC with FA decreased more significantly. Nevertheless, the reduction in Gs was quite small when the FA content was higher than $25 \%$ by weight of dry soil.

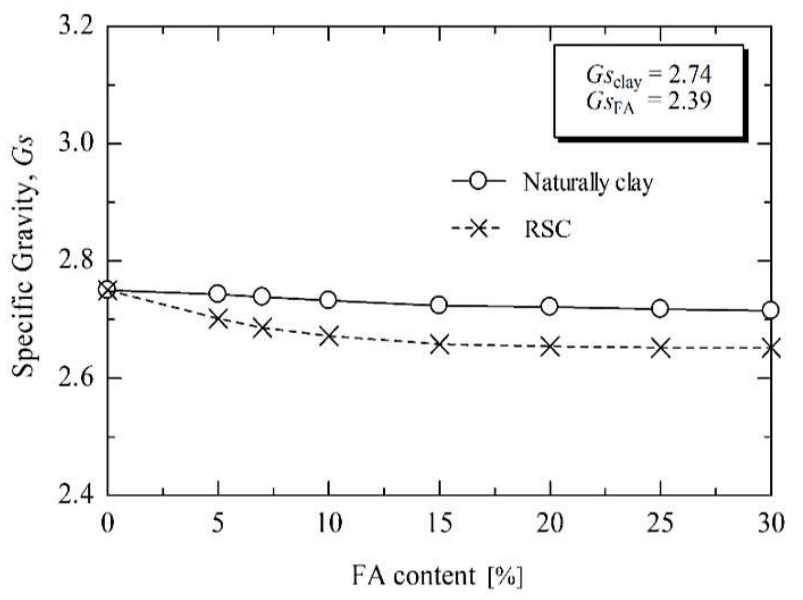

Fig. 4: Influence of FA on Gs of the clay and RSC samples with FA at 28-day curing.

The results of plasticity index of clay and RSC with FA after curing for 28 days curing are shown in Fig. 5. The liquid limits (LL) of clay and RSC were similar $54-55 \%$. The LL of clay was relatively constant. While the plastic limits (PL) of clay and RSC with FA slightly decreased with increase in FA content. The decrease in PL resulted in the increase in plasticity index (PI). Fig. 5 showed that the PI of RSC with FA was lower than that of clay with FA.
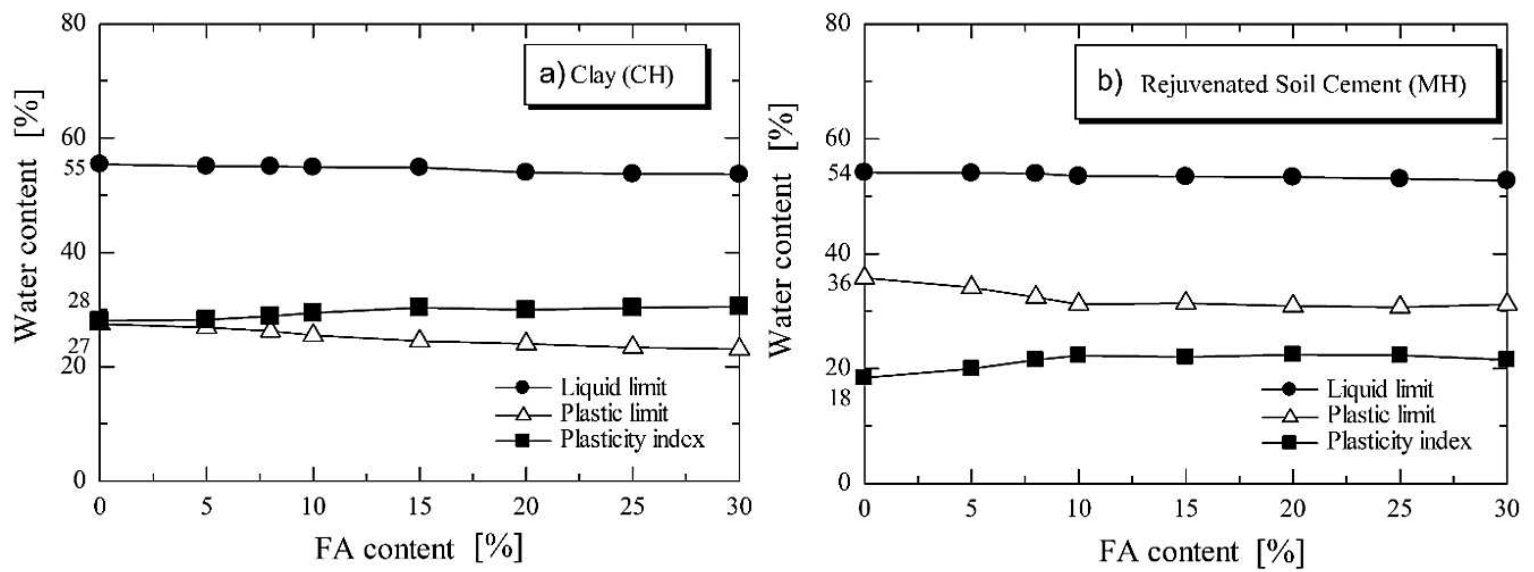

Fig. 5: Influence of FA on plasticity index of a) clay, and b) RSC with FA samples at 28-day curing. 
Fig. 6 presents the result on the swelling behavior in terms of free swell ratio (FSR) of the clay and RSC stabilized with FA at 28-day curing. The FSR of clay and RSC (without FA) were 1.76 and 1.30 respectively. The FSR of both samples clearly decreased with the increase in FA. The FSR of RSC tended to decline when the FA content decreased. The FSR of clay with FA also decreased with the increase in FA content until FA content was about $15 \%$ and remained constant at 1.10 thereafter. However, the FSR of RSC was significantly lower than that of clay and the FA content of $25 \%$ was appropriate to stabilize the FSR in terms of the swelling.

Fig. 7 shows the results of linear shrinkage of clay and RSC stabilized with FA at 28-day curing. The linear shrinkages of clay and SC (without FA) were $12.7 \%$ and $5.2 \%$, respectively. The linear shrinkage of the two samples decreased with the increase in FA. It was also shown that the linear shrinkage of RSC was lower than that of clay.

Figs. 8 and 9 describe the dry unit weight and water content relationship under the compaction test by modified compaction test method for clay, SC (without FA), and RSC stabilized with FA. From Fig. 8 the maximum dry unit weight of RSC is slightly higher than that of clay while the optimum moisture contents are similar. When mixing RSC with FA, the maximum dry unit weight of RSC increased with the increase in FA content up to $15 \%$ by weight of dry soil. However, beyond the FA content of $15 \%$, the maximum dry unit weight of samples was considerably reduced. However, the optimum water content did not change with the increasing of FA content. The influence of FA on maximum dry unit weight and optimum water content of RSC stabilized with FA are shown in Figs. 10 and 11.

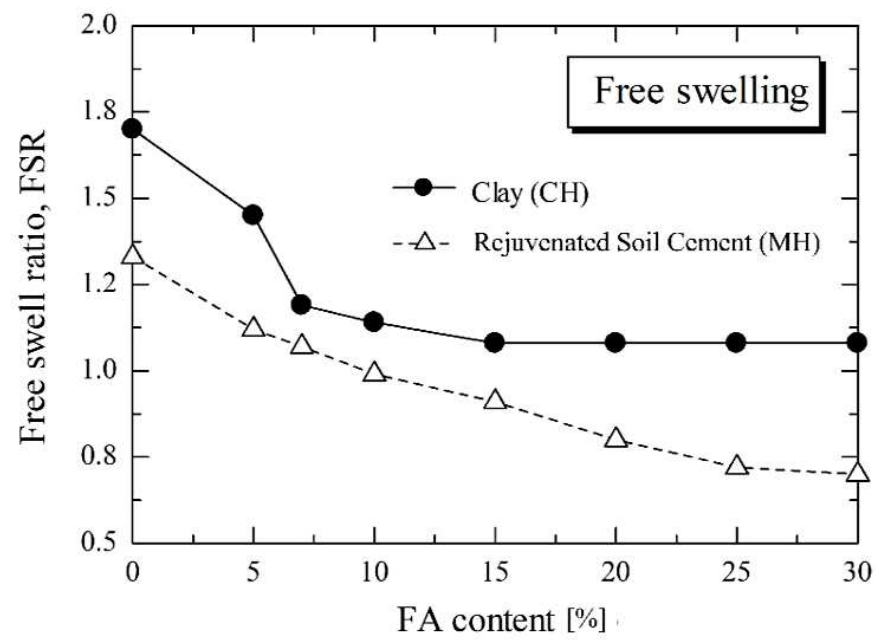

Fig. 6: Influence of FA on free swell ratio of clay and RSC with FA tested with remolded samples after 28 days curing.

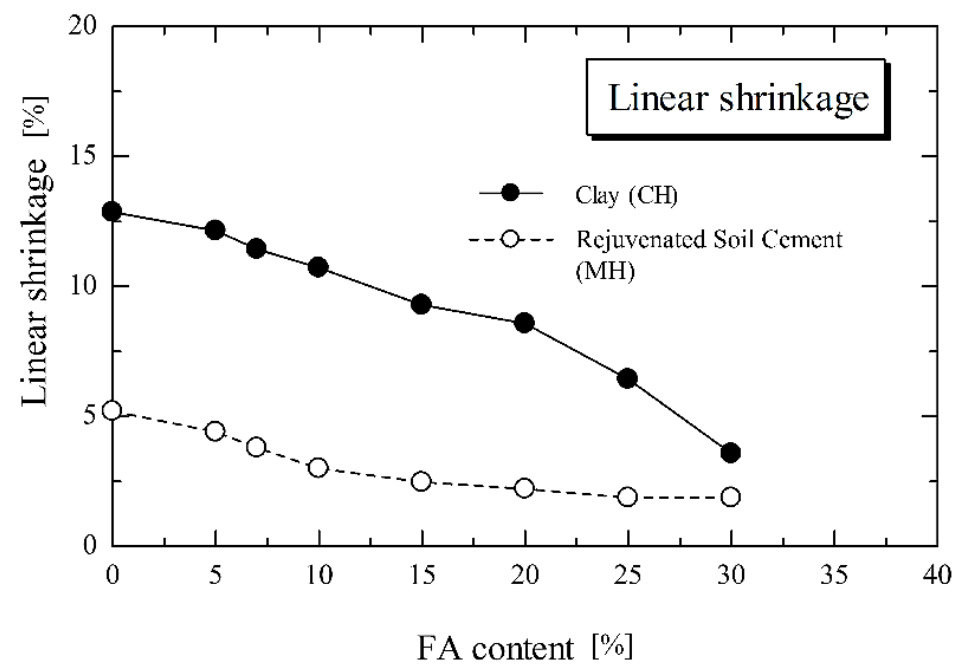

Fig. 7: Influence of FA on linear shrinkage of clay and RSC with FA at 28-day curing. 


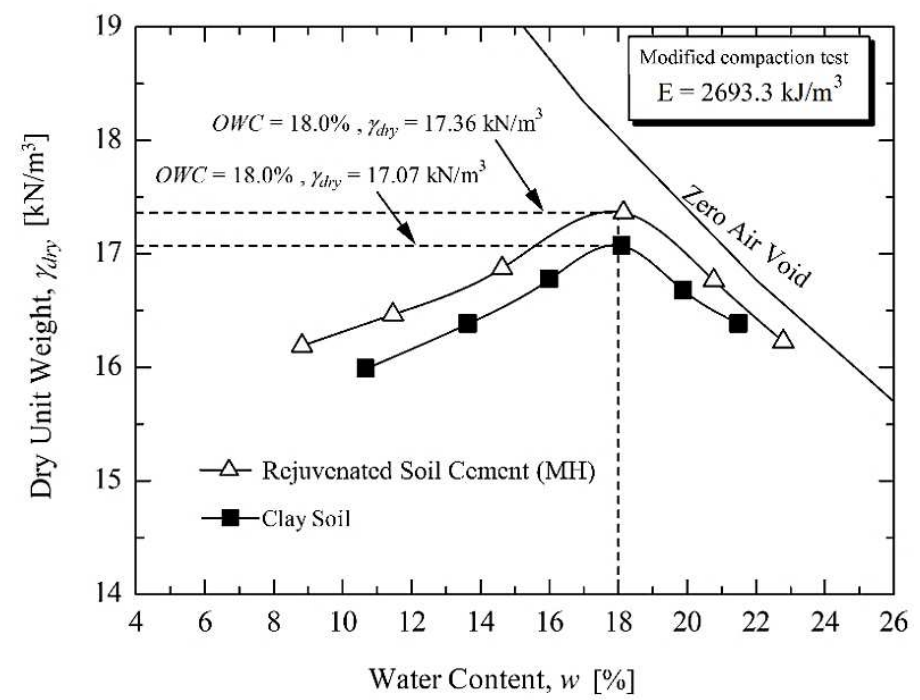

Fig. 8: Dry unit weight and water content of clay and RSC with modified compaction.

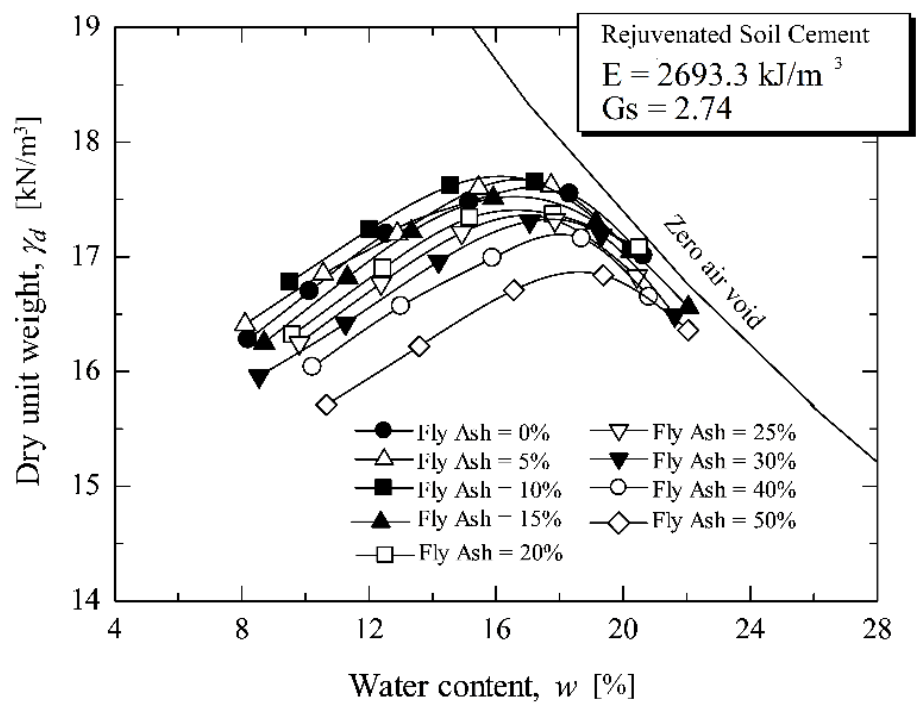

Fig. 9: Dry unit weight and water content of clay and RSC with FA with modified compaction.

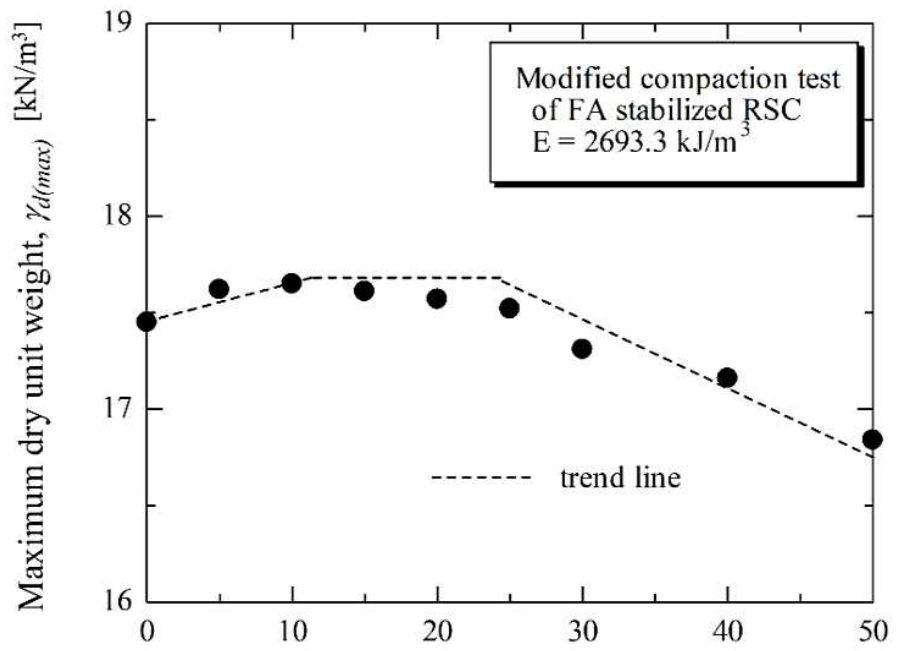

Fly ash content $[\%]$

Fig. 10: Maximum dry unit weight of RSC with FA with modified compaction. 


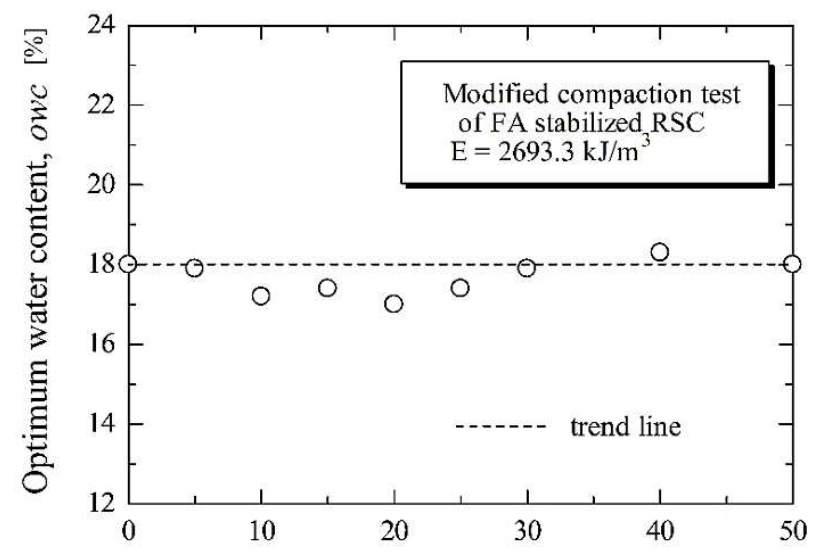

Fly ash content $[\%]$

Fig. 11: Water content of RSC with FA compacted with modified compaction.

From the results of UCS of RSC stabilized with $0-50 \%$ FA by weight of dry soil tested at 7 and 28 days of curing, it was found that the maximum UCS of RSC stabilized with FA increased with the increase in FA. The suitable FA content (at the maximum UCS) of samples after 7 and 28 days curing were $20 \%$ and $25 \%$ as shown in Fig. 12. Therefore, the content of FA with the increase in strength of RSC was called "active zone", whereas "deterioration zone" was the zone for the strength decline.

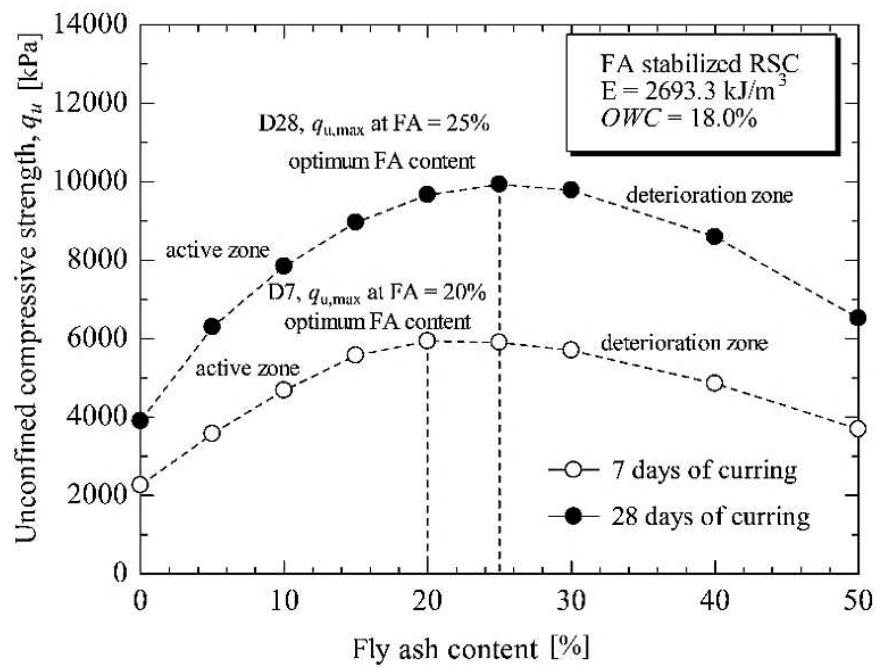

Fig. 12: Relationship between UCS and FA content of RSC after 7 days and 28 days of curing.

\section{Analysis and discussion}

The effect of rehydration and pozzolanic reaction between $F A$ and free lime significantly influenced the Gs, index properties and swelling properties of soil treated by FA see Fig. 4 - Fig. 7 which were clearly observed by the difference of the results from samples with and without curing.

The decrease in Gs with increasing FA content as shown in Fig. 4 was affected by the increase of void ratio of RSC. The decrease in Gs of RSC stabilized with FA was due to the low Gs of FA 2.30 compared with that of clay 2.74 and the associated expansion as the result of rehydration of RSC and pozzolanic reaction between FA and free lime [20].

From the compaction graph, the maximum dry unit weight of RSC was higher than that of natural clay with the same optimum water content, Fig. 8. The presence of cement and free lime in RSC resulted in the $\mathrm{Ca}^{2+}$ absorption onto the surface of particles and led to a reduction in the soil particles attractive force and created edge-to-face arrangement [21-22].

From Figs. 9 and 10, the use of FA resulted in increased RSC maximum dry unit weight initially. Further increase in the FA content resulted in a suitable FA content with maximum dry unit weight whereby the soil particles in RSC were assembled together coinciding with forming a larger lump and notably increasing the plasticity index, Fig. 5, which therefore reduced the swelling and shrinkage, Figs. 6 and 7. 
The same optimum water content of RSC was observed with increasing FA content. This mechanism was associated with a low plasticity of clay. The test results were in line with the previously reported work on the silty clay mixed with cement [23]. Since the liquid limit controlled the OWC of the low plasticity of clay [24], therefore, the optimum water contents of RSC stabilized with FA were similar, Fig. 11.

The USC of RSC stabilized with FA increased with the increase in FA and curing period, Fig. 12. This was the result from the influences of several components viz., compaction effect, filling effect of FA in voids amongst the soil grains, rehydration effect of un-hydrated cement due to shallow mixing with very low water to soil-cement ratio, and pozzolanic reaction. The results of USC test of RSC stabilized with FA are presented in Fig. 13. The pozzolanic reaction and rehydration reaction were the key factors for the strength improvement of RSC stabilized with FA resulting in the increasing of compressive strength with curing. The others were the compaction effect (the soil particle arrangement by compaction) and packing effect from FA small particles. Similar finding was reported by Kampala et al. [9].

The role of FA on strength development of RSC stabilized with FA could be described by SEM (Scanning Electron Microscope) photos as illustrated in Figs. 14a-14d, The result from packing effect was due to filling or packing of the fine FA particles into the void between the soil grain as shown in Fig. 14a, With curing time, the pozzolanic reaction between $\mathrm{Ca}(\mathrm{OH})_{2}$ and $\mathrm{FA}$ increased, and the products were deposited on the surface of FA particles as shown in Figs. 14b -14d, The increase in pozzolanic reaction with curing time was also reported by Horpibulsuk [2] and Massazza [25].

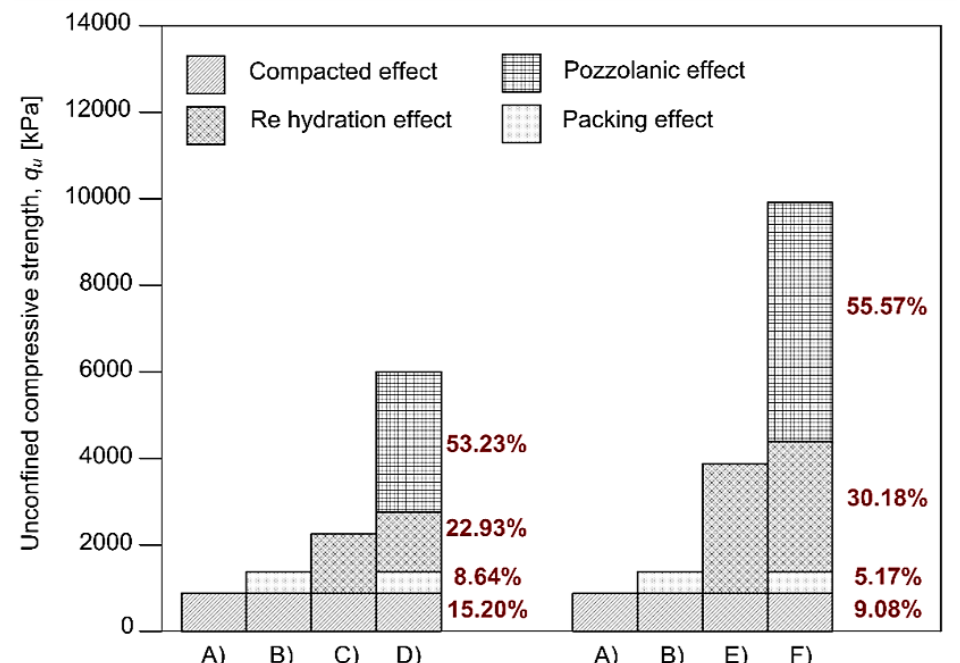
A) RSC no curing
B) RSC+FA20\% no curing
C) RSC at 7 days of curing
D) RSC+FA20\% at 7 days of curing
E) RSC at 28 days of curing
F) $\mathrm{RSC}+\mathrm{FA} 20 \%$ at 28 days of curing

Fig. 13: Influences on unconfined compressive strength of RSC stabilized with FA.

Fig. 15 illustrates the compressive strength improvement of clay and RSC stabilized with FA. The natural clay with FA alone did not show any strength suggesting that the compaction effect and packing effect alone was not sufficient in stabilizing natural soil. The soil sample collapsed with no strength after being soaked in water for only a few minutes. While the UCS of RSC stabilized with FA in active zone $0-25 \%$ were considerable and increased with the increase in FA content and curing time which indicated the rehydration effect and pozzolanic effect. The FA content over $25 \%$ (30 - $50 \%$ resulted in deterioration zone and thus was not taken into account. Presenting this result with curing time in a semi-logarithm scale, the relationship of strength and curing time showed a linear relationship as shown in Fig. 16.

In general, the compressive strength of pavement should be tested at 7 and 28 days of curing. The curing period for the designed strength for sub-base layer of soil cement according to ACI230.1R90 [19] the compressive strength at 7 and 28 days which are $1724 \mathrm{kPa}$ and $2068 \mathrm{kPa}$ respectively.

When the compressive strength at any curing period was normalized against the compressive strength at 7 and 28 days of curing, the relationship of compressive strength and curing period plotted in a semi-logarithm scale was linear as shown in Fig. 16. This established relationship could then be 
used to estimate the compressive strengths at 7 and 28 days of curing. From the tests, Eq. (1) and (2) for the compressive strengths at 7 days and 28 days of curing were established as follows:

Equation (1) is for the compressive strength estimation at 7 days of curing.

$\frac{q_{D}}{q_{7}}=0.0615+1.127 \log (D)$,

where $D=1-7$ days of curing.

Equation (2) is for the compressive strength estimation at 28 days of curing.

$\frac{q_{D}}{q_{28}}=0.0355+0.649 \log (D)$,

where $D=1-14$ days of curing.

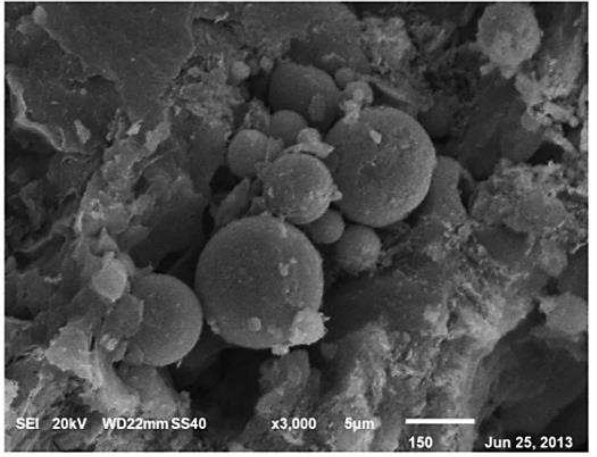

a) 1-day of curing

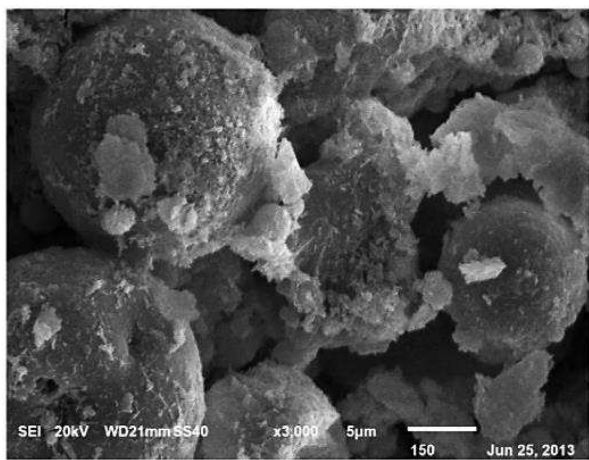

c) 14-days of curing

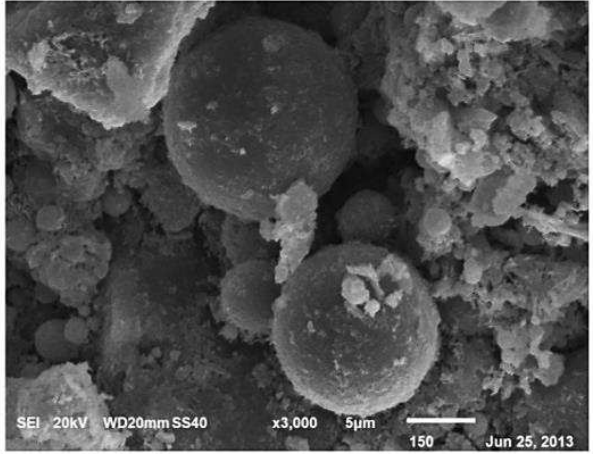

b) 7-days of curing

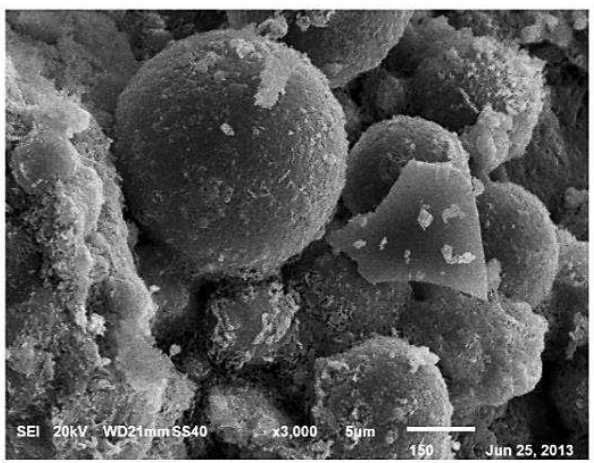

d) 28-days of curing

Fig. 14: SEM photos of $25 \%$ FA stabilized RSC at: a) 1 day, b) 7 days, c) 14 days, and d) 28 days of curing.

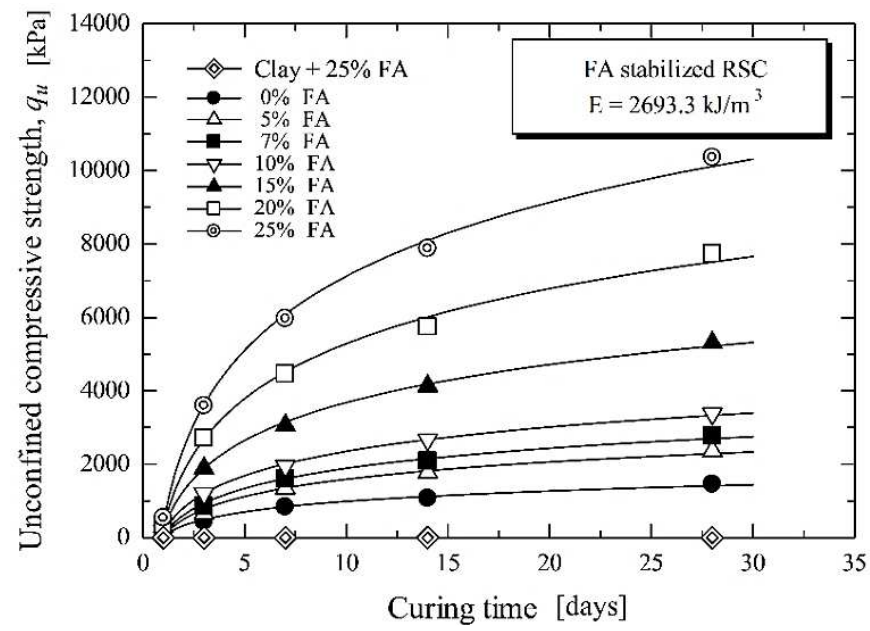

Fig. 15: Soaked strength of clay and RSC with FA. 

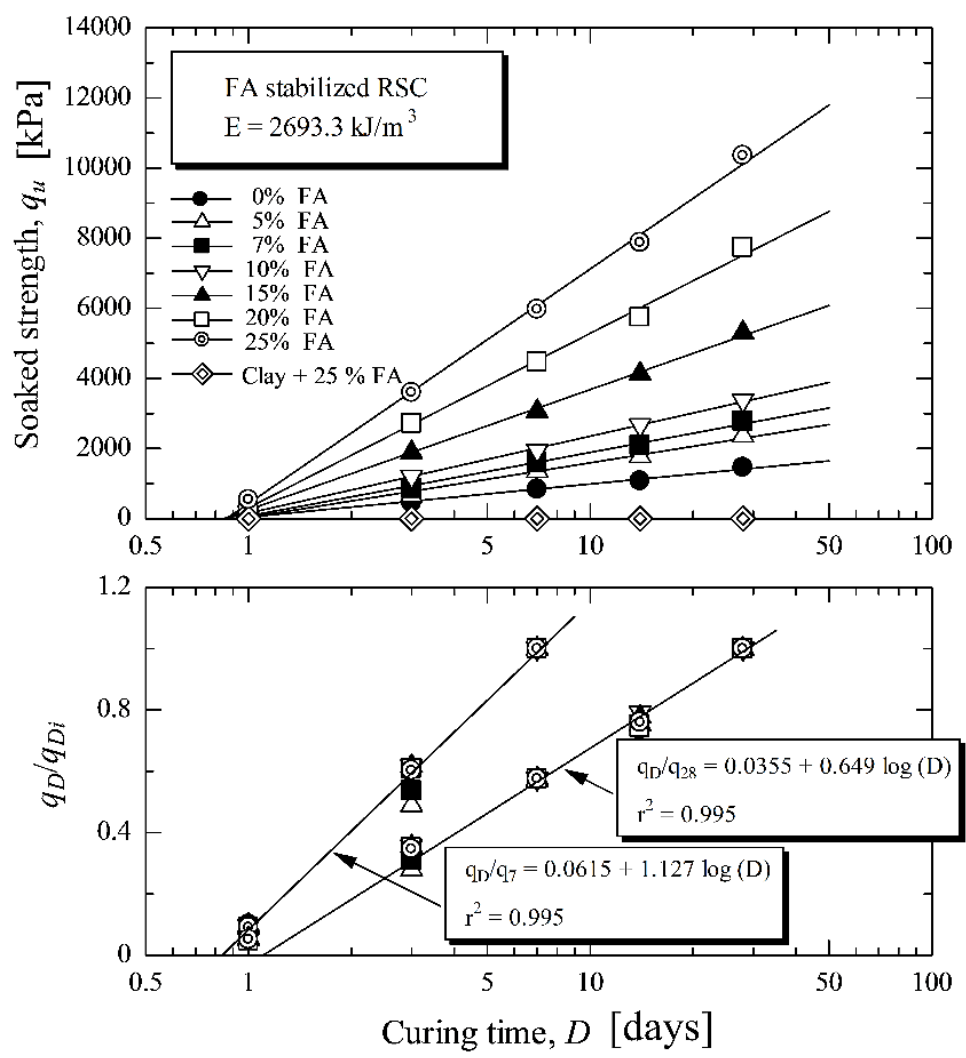

Fig. 16: Development of strength with time of FA stabilized RSC and normalization.

Generally, this relationship could be used to estimate the compressive strength of clay with lime and FA at 28 days of curing from the compressive strength test result at 7 days [14] and estimate the strength of silty clay with calcium carbide residue and FA at 28 days curing [15]. The result of compressive strength test at 7 and 28 days curing and the strength calculated from Eq. (1) and (2) were comparable and presented in Fig. 17. This confirmed that the equations gained from the compressive strength tests at 7 days and 28 days of curing could be used for the pavement work design. The knowledge obtained from the results of compressive stress and axial strain which is the relationship of modulus of elasticity, $E_{50}$ and unconfined compressive strength $q_{u}$ of FA stabilized RSC at 7 and 28 days curing time could also be established as illustrated in Fig. 18. This could also be used to estimate the elastic of deformation on pavement structure or embankment in soil rejuvenated pavement application.

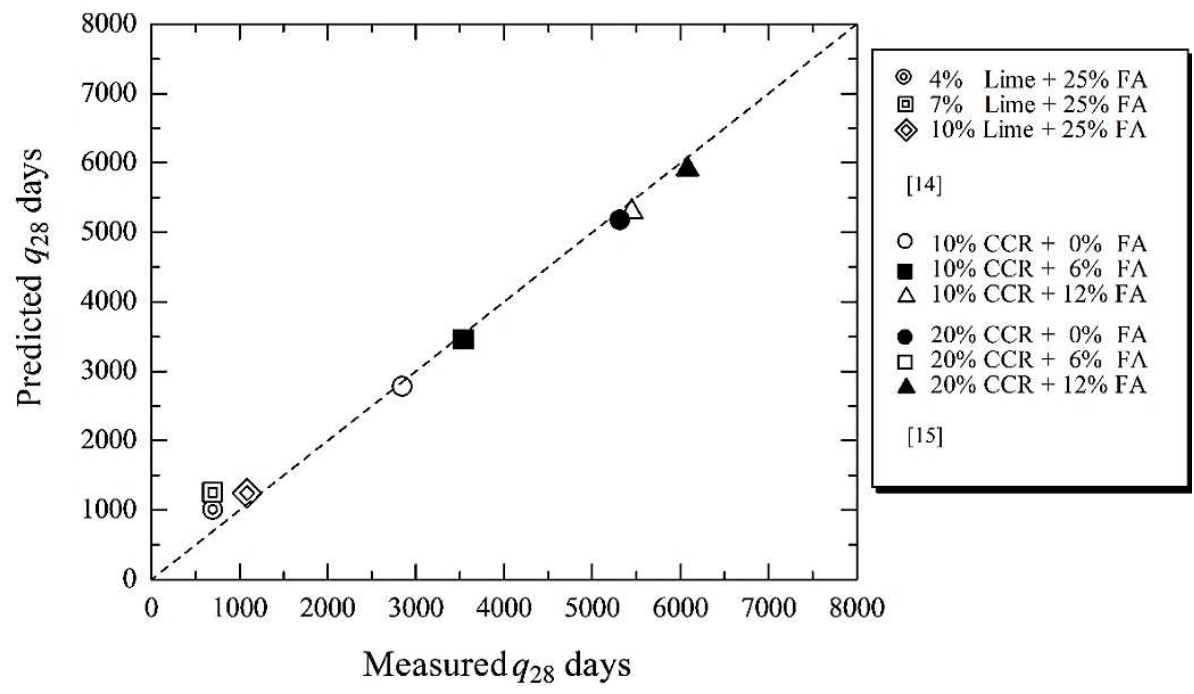

Fig. 17: Measured and predicted soaked strengths at 28 days curing. 


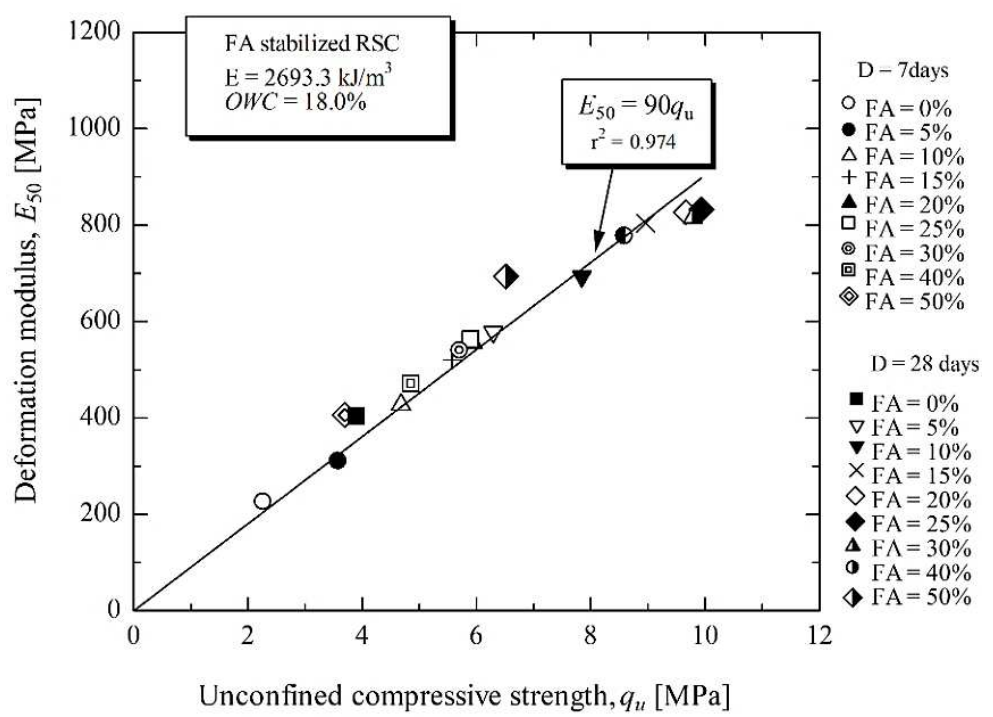

Fig. 18: Relationship between secant modulus of elasticity, $E_{50}$ and UCS, $q_{u}$ of FA stabilized RSC at 7 and 28 days curing.

\section{Conclusions}

Based on the study on the influences of FA on basic and strength properties of the RSC with $F A$, the findings could be summarized as follows:

1) The decrease of Gs of RSC is due to the low Gs of FA 2.30 compared to that of clay 2.74 , and the expansion due to rehydration and pozzolanic reaction between FA and free lime.

2) The liquid limit indices of clay and RSC are similar (approximately $54-55 \%$ ) and the liquid limit of clay is relatively constant and does not change with FA content. Whereas the plastic limit of clay and RSC stabilized with FA slightly decreased with the increase in FA. Consequently, the decrease in $\mathrm{PL}$ resulted in the increase in plasticity index (PI) of both samples. In most cases, the PI of RSC mixed with FA was lower than that of clay with FA.

3) The free swell ratio (FSR) and linear shrinkage of clay and SC (without FA) were 1.76 and 1.30 respectively. Whereas the linear shrinkage of clay and RSC (with FA) were $12.7 \%$ and $5.2 \%$ respectively. Thus, the FSR and linear shrinkage of RSC were significantly lower than those of clay. Additionally, the FSR and linear shrinkage of both samples tended to decrease by the increasing FA content.

4) The maximum dry unit weight of RSC was slightly higher than that of clay while the optimum moisture contents of both were similar. When mixing RSC with FA, the maximum dry unit weight of RSC increased with the increasing FA up to $15 \%$. After that, the maximum dry unit weight decreased with the increase in FA. However, the optimum water content is quite stable and does not change with the increasing FA.

5) The strength improvement of FA stabilized RSC was influenced by four mechanisms viz., compaction effect, packing effect, rehydration effect, and pozzolanic reaction effect.

6) The compressive strength of RSC stabilization with FA increased with increase in FA up to $25 \%$. The relation between compressive strength and curing time is linear when plotted in a semilogarithm form. When the compressive strength at any curing period is normalized against the compressive strengths at 7 and 28 days of curing, the relationship became linear. This established relationship can be used to estimate the compressive strengths at 7 days and 28 days of any curing period.

7) The relationship between secant modulus of elasticity, $E_{50}$ and UCS of FA stabilized RSC at 7 days and 28 days curing time can also be established. This established relationship can also be used to estimate the modulus of elasticity on pavement structure or embankment in soil recycled pavement application.

\section{Acknowledgements}

The authors acknowledge the financial support provided by Faculty of Engineering, Rajamangala University of Technology Isan KhonKaen Campus. The first author would also like to acknowledge the "Support by Research and Graduate Studies" Khon Kaen University. 


\section{References}

[1] MIURA, N. - HORPIBULSUK, S. - NAGARAJ, T. S.: Engineering Behavior of Cement Stabilized Clay at High Water Content. Soils and Foundations, Vol. 41, Iss. 5, 2001, pp. 33-45.

[2] HORPIBULSUK. S, - RACHAN, R. - RAKSACHON, Y.: Role of Fly Ash on Strength and Microstructure Development in Blended Cement Stabilized Silty Clay. Soils and Foundations, Vol. 49, Iss. 1, 2009, pp. 85-98.

[3] NOULMANEE, A. - PRONGMANEE, N. - PUKDEE, W. - SINGHAN, P.: Compressive Strengths of Pavement Recycling Materials and New Approach for Cement Content Determination. Civil and Environmental Engineering, Vol. 17, Iss. 1, 2021, pp. 335-342.

[4] ISAIA, G. C. - GASTALDINI, A. L. G. - MORAES, R.: Physical and Pozzolanic Action of Mineral Additions on the Mechanical Strength of High-Performance Concrete. Cement and Concrete Composite, Vol. 25, Iss. 1, 2003, pp. 69-76.

[5] KAMPALA, A. - HORPIBULSUK, S. - CHINKULKIJNIWAT, A. - SHEN, S. L.: Engineering Properties of Recycled Calcium Carbide Residue Stabilzed Clay as Fill and Pavement Materials. Construction and Building Materials, Vol. 46, 2013, pp. 203-210.

[6] GOPALSAMY, P. - POORNIMA, E. - KARTHICK, P.: An Experimental Investigation on Properties of Concrete by Using Activated Fly Ash. International Research Journal of Advance Engineering and Science, Vol. 1, Iss. 2, 2016, pp. 109-113.

[7] SARASWATHY, V. - MURALIDHARAN, S. - THANGAVEL, K. - SRINIVASAN, S.: Influence of Activated Fly Ash on Corrosion-Resistance and Strength of Concrete. Cement and Concrete Composite, Vol. 25, Iss. 7, 2003, pp. 673-680.

[8] POTHA, R.M. - SHOBHA, M. - RAMBABU, K.: Flexural Strength of Fly Ash Concrete under Elevated Temperatures. Magazine of Concrete Research, Vol. 56, Iss. 2, 2004, p. 83-88.

[9] SIDDIQUE, R.: Performance Characteristics of High-Volume Class F Fly Ash concrete. Cement and Concrete Research, Vol. 34, Iss. 3 2004, pp. 487-493.

[10] CHEN, Y. - GAO, J. - TANG, L. - LI, X.: Resistance of Concrete against Combined Attack of Chloride and Sulfate under Drying-Wetting Cycles. Construction and Building Materials, Vol. 106, 2016, pp. 650-658.

[11] GONG, J. - CAO, J. - WANG, Y. F.: Effects of Sulfate Attack and Dry-Wet Circulation on Creep of Fly-Ash Slag Concrete. Construction and Building Materials, Vol. 125, 2016, pp. 12-20.

[12] AKBULUT, S. - SAGLAMER, A.: Evaluation of Fly Ash and Clay in Soil Grouting. Grouting and Ground Treatment. ASCE, Vol. 67, 2003, pp. 1192-1199.

[13] COKCA, E.: Use of Class C Fly Ashes for the Stabilization of an Expansive Soil. Journal of Geotechnical and Geoenvireonmental Engineering. Vol. 127, Iss. 7, 2001, pp. 568-573.

[14] CONSOLI, N. C. - PRIETTO, P. D. M. - CARRARO, J. A. H.: Behavior of Compacted Soil-Fly Ash-Carbide Lime Mixtures, Journal of Geotechnical and Geoenvireonmental Engineering, Vol. 127, Iss. 9, 2001, pp. 774-782.

[15] HORPIBULSUK, S. - PHETCHUAY, C. - CHINKULKIJNNIWAT, A. - HOLAPHATSORN, A.: Strength Development in Silty Clay Stabilized with Calcium Carbide Residue and Fly Ash. Soils and Foundations, Vol. 53, Iss. 4, 2013, pp. 477-486.

[16] McCARTHY, M. J. - CSETENYI, L. - SACHDEVA, A. - DHIR, R.: Engineering and Durability Properties of Fly Ash Treated Lime-Stabilized Sulfate-Bearing soils. Engineering Geology, Vol. 174,2014, p. 03.001

[17] MARANDI-AGHABAGLOU, A. - ANDIC-CAKIR, O. - RAMYAR, K.: Freeze-Thaw Resistance and Transport Properties of High-Volume Fly Ash Roller Compacted Concrete Designed by Maximum Density Method. Cement and Concrete Composite, Vol. 37, 2013, pp. 259-266.

[18] PRAKASH, K. - SRIDHARAN, A.: Free Swell Ratio and Clay Mineralogy of Fine-Grained Soils. Geotechnical Testing Journal, Vol. 27, Iss. 2, 2004, pp. 220-225.

[19] ACI 230.1R-90.: State-of-the-Art Report on Soil Cement. ACI Committee 230, 1997, pp. 1-23.

[20] LOCAT, J. - ANDRE, B. M. - CHOQUETTE, M.: Laboratory Investigations on the Lime Stabilization of Sensitive Clays: Shear Strength Development. Canndian Geotechnical Journal, Vol. 27, 1990, pp. 294-304.

[21] ATTAH, I. C. - ETIM, R. K. - YOHANNA, P. - USANGA, I. N.: Understanding the effect of compaction energies on the strength indices and durability of oyster shell ash-lateritic soil mixtures for use in road works. Engineering and Applied Science Research, Vol. 48, Iss. 2, 2021, pp. 151-160, https://ph01.tci-thaijo.org/index.php/easr/article/view/240358.

[22] CHEW, S. H. - KAMARUZZAMAN, A. H. M. - LEE, F. H.: Physicochemical and Engineering Behavior of Cement Treated Clays. Journal of Geotechnical and Geoenvironmental Engineering. Vol. 130, Iss. 7, 2004, pp. 696-706. 
[23] NAGARAJ, T. S. - LUTENEGGER, A. - PANDIAN, N. - MANOJ, M.: Rapid Estimation of Compaction Parameters for Field Control. Geotechnical Testing Journal. Vol. 29, Iss. 6, 2006, pp. 1-10.

[24] GURTUG, Y. - SRIDHARAN, A.: Compaction Behaviour and Prediction of Its Characteristics of Fine Grained Soils with Particular Reference to Compaction Energy. Soils and Foundations, Vol. 44, Iss. 5, 2004, pp. 27-36.

[25] MASSAZZA, P.: Pozzolana and Pozzolanic Cements. Lea's Chemistry of Cement and Concrete. Arnold, London, 1998, pp. 471-631. 